\title{
CLINICAL IMPORTANCE OF SOLITARY SOLID NODULE OF THE THYROID IN ENDEMIC GOITER REGION
}

\author{
EMIN GURLEYIK, OZGUR COSKUN, ARIF ASLANER
}

\section{ABSTRACT}

CONTEXT : Endemic area and iodine supplementation may affect the pathogenesis of the nodule which commonly occurs in endemic thyroid enlargement due to iodine deficiency. AIMS : To establish pathological changes in solitary solid and larger nodule of the thyroid in endemic area. SETTING AND DESIGN: Retrospective study in Surgical Department of University Hospital. METHODS AND MATERIAL : We determined 44 surgically treated patients with solitary solid nodule in endemic goiter area in which the population routinely receives iodinated salt. The thyroid nodule was preoperatively evaluated with blood chemistry, ultrasound, nuclear scanning and FNAC. The results of preoperative evaluation, surgical interventions, and histopathological examination were analyzed. STATISTICAL ANALYSIS : Student $t$ test and Fisher's exact test. RESULTS: Twenty $(45 \% ; 20 / 44)$ patients with hot (autonomous) nodule have received the diagnosis of toxic adenoma. Twenty four patients had solitary solid and cold nodule. Total thyroidectomy was performed on two patients with papillary cancer (PTC) diagnosed by FNAC from cold nodules. Forty two patients have been treated with total excision of the lobe including hyper or hypoactive solitary solid nodule. Pathological examination has reported two more cases of PTC and one case of insular cancer arising from cold nodules. Completion thyroidectomy was performed on these 3 patients. CONCLUSIONS : Solitary solid and large nodule is a common indication for thyroid surgery in endemic goiter area. High incidence of hyperthyroidism due to single autonomous nodule, and high rate of malignant change (mainly papillary cancer) in solitary hypoactive nodule arises from this series in endemic thyroid enlargement.

KEY WORDS : Endemic goiter, solitary solid nodule, hyperthyroidism, papillary cancer, toxic adenoma, thyroidectomy.

\section{INTRODUCTION}

Our institution is located in an endemic goiter area due to iodine deficiency. Alimentary iodine supplementation is a worldwide method to resolve this health problem as routinely did in our region in the last 15 years. Hypertrophy

Department of Surgery, Abant Izzet Baysal University, Duzce Medical Faculty, of the thyroid and nodular formation in the gland is a common occurrence in endemic region. It has been reported that exogenous iodine intake affects the pathogenesis of thyroid nodules. ${ }^{[1-7]}$. Palpable thyroid nodule(s) of which great majority are asymptomatic occurs in 5\% of the population. ${ }^{[8-10]}$

Correspondence

Emin Gurleyik

Duzce Tip Fakultesi, Konuralp 81620, Duzce, TURKEY.

Fax: 00903805414105

E-mail: egurleyik@yahoo.com 
Approximately $5 \%$ of all palpable thyroid nodules have been reported as malignant. ${ }^{[10]}$ Some predisposing pathological features increase clinical importance of thyroid nodule(s). A significant feature is nodule size. A palpable thyroid nodule at physical examination, especially greater than $2 \mathrm{~cm}$ of diameter carries a considerable risk of annoying disorder. ${ }^{[11-13]}$ Another main feature is structural (solid and cystic) nature of the nodule. Especially, management of a larger solid nodule merits a distinct importance. ${ }^{[11,12,14,15]} \mathrm{A}$ third feature is functional status of the nodule. The activity of a nodule may be established by chemical hormonal analysis and nuclear imaging method. A hyperactive or hypoactive nodule significantly influences clinical outcome of a patient. ${ }^{[9,10,16,17]}$ A forth important characteristic of the nodule is its solitary feature. A solitary nodule carries greater clinical importance than multinodular formation. ${ }^{[14,18]}$ Based on clinical, chemical and image characteristics, the thyroid nodule which possess all these four pathological features ("large size", "solitary", "solid", "hypo or hyperactive") is generally treated by surgical intervention.

In this study, we aimed to analyze our surgically treated patients with palpable solitary solid nodule of the thyroid in an endemic goiter area due to low iodine intake.

\section{METHODS}

In a period of 6 years (Between 1999 and 2005), hospital and operative records of 253 patients with nodular goiter were retrospectively analyzed. We determined 44 (17.4\%) patients who have palpable solitary solid nodule of the thyroid gland.

Demography : Our series have a mean age of $48(21-75)$ years, and thirty-two $(73 \% ; 32 / 44)$ patients were female.

Blood chemistry : Thyroid function was established biochemically by measurement of serum concentrations of thyroid stimulating hormone (TSH), free triiodothyronine (FT3) free thyroxin (FT4)

Ultrasound : The thyroid was examined by high resolution ultrasound. This examination has evaluated the size, echo-structure (solid or cystic), shape and number of nodule(s), and extranodular thyroid tissue. The presence of single (solitary) solid nodule in one lobe of the gland, and relatively homogeneous extranodular tissue has been reported in all our 44 cases.

Nuclear imaging: Thyroid scintigraphy with $99 \mathrm{mTc}$ pertechnate has evaluated functional status of the nodule and extranodular tissue. Single hot spot and suppressed extranodular tissue in nuclear scanning has showed solitary nodule which intensively concentrated the radioisotope by autonomous hyperactivity. Single cold spot in nuclear scanning has established hypo- or non-functional status of solitary solid nodule that this nodule has had cellular structure which has not had the ability to concentrate the radioisotope.

Pathologic anatomy : Fine needle aspiration cytology (FNAC) was performed on al palpable nodules of 44 patients either directly or by ultrasound guide. Postoperatively, the histopathological examination of excised thyroid tissue has reported the final diagnosis The results of physical examination, blood chemistry, ultrasound and nuclear imaging have indicated surgical management of our patients with solitary solid nodule of the thyroid. Our cases of hyperthyroidism were medically controlled with antithyroid drugs before the operation. We analyzed demographic features of patients, results of preoperative evaluation, surgical methods, final pathological diagnosis and postoperative outcome of patients.

Statistical analysis : Statistical analysis was made using student $t$ test and Fisher's exact test, and $p<0.05$ was accepted as significant. Results

Preoperative evaluation : We determined 32 Table 1 : Preoperative evaluation of patients.

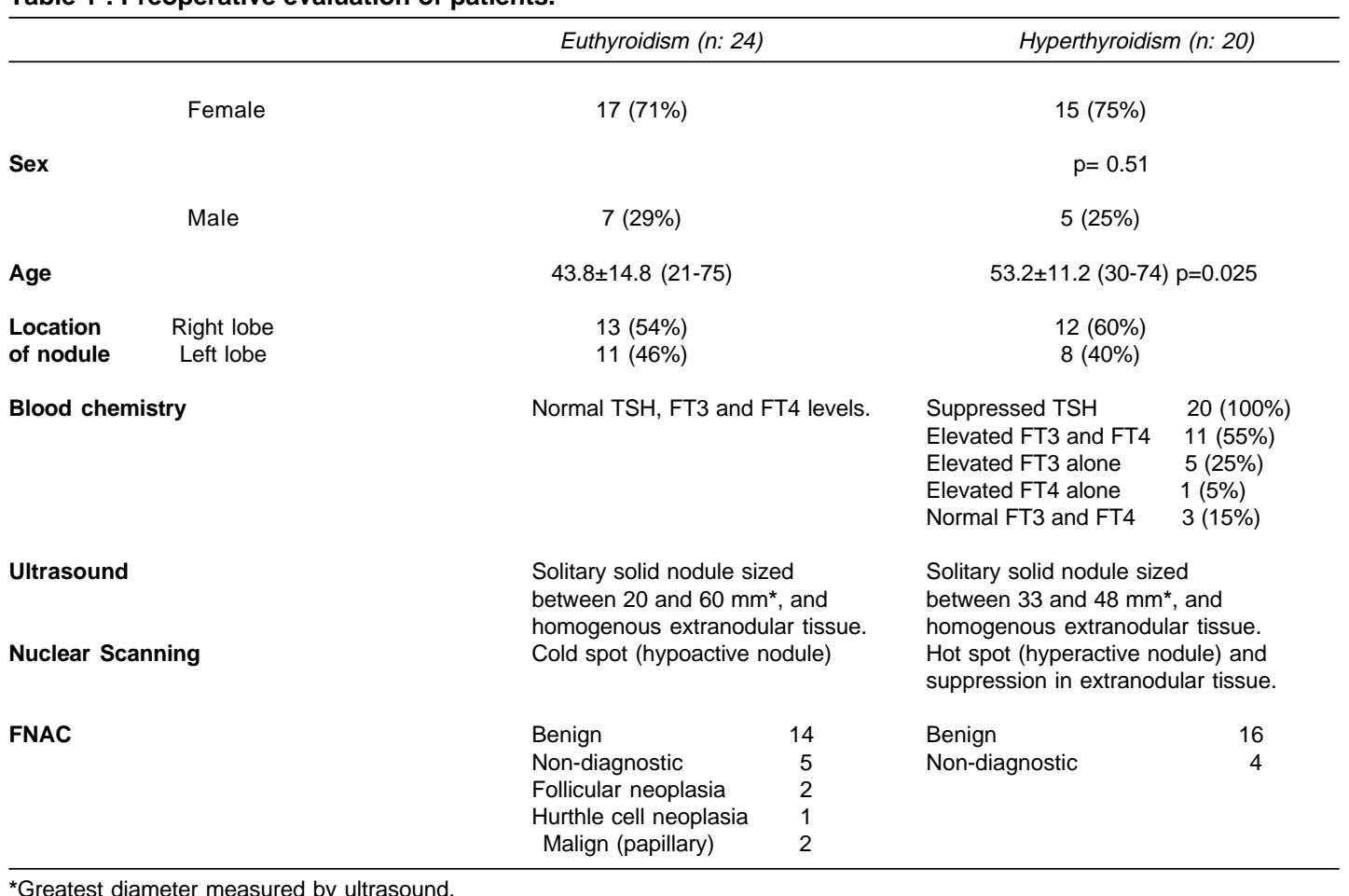

${ }^{*}$ Greatest diameter measured by ultrasound.

(73\%) female and 12 male patients with solitary solid nodule of the thyroid who were surgically treated after preoperative evaluation. Blood chemistry has showed hyperthyroidism in $20(45 \%)$ patients. Ultrasonography has diagnosed solitary, solid nodule in all 44 patients. Nuclear scanning has imaged a large hot spot and suppressed extranodular thyroid tissue in 20 patients with clinical and chemical hyperthyroidism and large cold spot in the remaining 24 patients with normal thyroid activity. FNAC has diagnosed papillary thyroid carcinoma (PTC) in 2 patients with cold nodule reported by nuclear scanning (Table 1).

Diagnosis : Clinical and chemica hyperthyroidism and single hot spot by scintigraphy has leaded the diagnosis of toxic adenoma in 20 patients. Solitary solid nodule 
Table 2: Diagnosis and management of patients

\begin{tabular}{|c|c|c|c|c|}
\hline & Euthyroidism (n:24) & & Hyperthyroidism (n:20) & \\
\hline \multirow{4}{*}{$\begin{array}{l}\text { Preoperative } \\
\text { diagnosis }\end{array}$} & Hypoactive nodule & 19 & \multirow{4}{*}{$\begin{array}{l}\text { Toxic adenoma } \\
\text { (Autonomous nodule) }\end{array}$} & 20 \\
\hline & Follicular neoplasia & 2 & & \\
\hline & Hurthle cell neoplasia & 1 & & \\
\hline & Papillary thyroid cancer (by FNAC) & 2 & & \\
\hline \multirow[t]{2}{*}{ Surgery0 } & Unilateral total lobectomy & & \multirow{2}{*}{$\begin{array}{l}\text { Unilateral total lobectomy } \\
\text { and excision of the isthmus }\end{array}$} & \\
\hline & and excision of the isthmus & 22 & & 20 \\
\hline \multirow{5}{*}{ Pathology } & Papillary throid cancer & 4 & \multirow{7}{*}{ Benign adenoma. } & 20 \\
\hline & Poorly differentiated insular cancer & 1 & & \\
\hline & Follicular adenoma & 2 & & \\
\hline & Hurthle cell adenoma & 1 & & \\
\hline & Nodular colloidal goiter & 16 & & \\
\hline \multirow[t]{2}{*}{$2^{\text {nd }}$ Operation } & Completion thyroidectomy (for PTC) & 2 & & \\
\hline & $\begin{array}{l}\text { Completion thyroidectomy and } \\
\text { neck dissection (for insular Ca) }\end{array}$ & 1 & & \\
\hline
\end{tabular}

by ultrasound and cold spot by nuclear scanning in patients with normal thyroid activity has showed hypo- or inactive solid nodule in 24 patients.

The indication for surgery was toxic adenoma in 20, inactive solid nodule in 22 and PTC diagnosed by FNAC in 2 patients.

Surgery : Total thyroidectomy was performed on 2 patients with preoperative diagnosis of PTC, and unilateral total lobectomy and excision of the isthmus on the remaining 42 patients with hyperactive (hot) or hypoactive (cold) nodule.

Pathology : In addition of 2 PTC cases, malignancy was reported by postoperative histopathologic examination in 3 patients with non-diagnostic FNAC (Table 2). Therefore, the rate of cancer was $21 \%(5 / 24)$ in patients with solitary solid hypoactive (cold) nodule.

Secondary surgery : A secondary operation for total excision of the remaining contralateral lobe (completion thyroidectomy) was performed on three patients in whom pathologic examination has established the diagnosis of malignancy in previously excised lobe. Functional neck dissection was added to completion thyroidectomy in our patient who has had pathological diagnosis of poorly differentiated insular carcinoma. Fortunately, this patient did not have involvemen contralateral lobe, extrathyroidal extension, lymphatic and distant metastasis.

Early postoperative management : The recovery was uneventful in all patients. Five malignant cases treated with total thyroidectomy have received a suppressive dose of L-thyroxin. Postoperatively, serum levels of TSH were in normal range in 39 patients treated with unilateral total lobectomy.

\section{DISCUSSION}

Alimentary iodine intake by iodinated salts has been programmed in the last 15 years for resolving the iodine deficiency in our region On the other hand, exogenous iodine supplementation affects the pathogenesis of the present nodule. Autonomy of some nodules leads to thyrotoxicosis in some middle and advanced aged patients with nodular goiter. Type of malignant progression has also been affected by exogenous iodine intake..$^{[1-7]}$ It has been reported that solitary, solid and large sized nodule possesses a different clinical and pathological significance for surgical evaluation. ${ }^{[19-21]}$ In this study we analyzed our surgically treated patients with solitary solid and larger nodule which has occurred in endemic thyroid enlargement.

High resolution ultrasound is the best imaging modality for objectively detecting size, number and cellular nature of the nodules. ${ }^{[22-25]}$ In our series ultrasound imaging single large nodule and relatively homogeneous extranodular tissue has confirmed the presence of solitary nodule in all patients. Solid nodule (less than $25 \%$ of cystic component) in ultrasound image has merited further careful evaluation and eventual indication for surgical intervention. On the other hand ultrasound has not the ability to establish functional status of the nodule. Nuclear imaging is a useful modality for the functional characterization of a thyroid nodule. ${ }^{[16,17]}$ In our series, nuclear scanning was found useful to define functional status of solitary solid nodule. Larger hot spot and image of suppressed extranodular tissue in the thyroid scintigraphy has identified hyperactive nodule, and has established the diagnosis of toxic adenoma in our 20 patients. Cold spot in the remaining 24 cases has determined hypo or inactive (functional status of the) solid nodule. Hypoactive solid nodule in nuclear scanning points out increased risk of malignancy. ${ }^{[18,26]}$ After imaging modalities FNAC is the preferred method for preoperative pathological evaluation.

Suppressed levels of TSH in our 20 patients, has established the diagnosis of hyperthyroidism. The cause of this hyperactivity was determined as larger autonomous nodule after findings of imaging studies. Advanced age of our patients with thyrotoxicosis and significant age difference between two groups has confirmed natural sequence in the pathogenesis of endemic goiter; diffuse thyroid enlargement, nodular formation in some cases and followed in time by autonomy of some nodules. Exogenous iodine intake can change clinical course of patients with nodular goiter such as hyperactive autonomy of nodule(s) triggered by iodine supplementation. ${ }^{[1-4]}$ Previous reports from endemic regions have also showed high rate of hyperthyroidism in elderly subjects induced by iodine intake..$^{[1,11,27]}$

As a scintigraphic feature, cold spot significantly increases the risk of malignancy in a large solid nodule. Solitary hypoactive solid nodule in our 24 patients has supported the indication of surgical intervention. Larger size, solitary nodule, echogenicity of solid elements, calcification, irregular shape as features of echotexture determined by ultrasound, and hypoactive nodule (cold spot) by nuclear scan have been reported as marker of high risk for malignant development. ${ }^{[18-}$ 21,23,25,26,28-30] The rate as $21 \%(5 / 24)$ of malignancy in our patients has confirmed increased risk of malignancy in larger hypoactive nodule. Previous studies have also reported similar rates of malignancy between $16 \%$ and $30 \%$ in solitary solid nodule. ${ }^{[14,18]}$ On the other hand the malignancy rate was $8.5 \%$ in autopsy and surgical series including solitary and multinodular goiter cases. ${ }^{[31-33]}$ FNAC which was diagnostic for papillary cancer has determined surgical method as total 
thyroidectomy in our two patients. According to our findings we can comment that when FNAC is not diagnostic for malignancy, total excision of the lobe including solid hypoactive nodule is the preferred method. Completion thyroidectomy may be indicated after histopathologic diagnosis of malignancy in the excised lobe as did in our three patients.

High incidence of follicular, poorly differentiated and anaplastic cancer had been previously reported from areas of endemic goiter due to iodine deficiency. ${ }^{[15,34,35]}$ Contrary, histopathologic findings in our series have showed high rate of well differentiated papillary type. It was reported that exogenous iodine intake has induced a significant change in histological type of nodule as an increase in papillary and a decrease in follicular and anaplastic types. ${ }^{[1,5-7,36]}$ Slowinska-Klecka et $\mathrm{a}^{\left[{ }^{[36]}\right.}$ and Burgess et al[5,6] have reported that a decrease in the diagnosis of follicular neoplasm and carcinoma, and an increase in the diagnosis of papillary type have been induced by routine iodine intake in order to correct its deficiency. Therefore we can suggest that exogenous iodine supplementation induces increased rate of well differentiated (papillary) cancer.

Although the number of patients is relatively small for definitive conclusion, based on our findings we have concluded that solitary solid and large nodule has a considerable rate among surgically treated patients with nodular goiter in endemic area. Ultrasound objectively defines cellular architecture of the nodule, and nuclear scan its functional status. High incidence of hyperthyroidism due to single autonomous nodule is a common finding in endemic goiter region. Solitary hypoactive and larger nodule possess high rate of malignant change. High rate of hyperthyroidism and well differentiated (papillary) thyroid cancer in larger solid nodule which occurs in endemic enlargement of the thyroid reveals potential influence of alimentary iodine supplementation on the pathogenesis of the nodule.

\section{REFERENCES}

1. Lind P, Kumnig G, Heinisch M, Igerc I, Mikosch $P$, Gallowitsch $\mathrm{HJ}$, et al. lodine supplementation in Austria: methods and results. Thyroid 2002;12:903-7.

2. Laurberg P, Bulow Pedersen I, Knudsen N, Ovesen L, Andersen S. Environmental iodine intake affects the type of nonmalignant thyroid disease. Thyroid 2001;11:457-69.

3. Niedziela M, Breborowicz D, Trejster E, Korman E. Hot nodules in children and adolescents in western Poland from 1996 to 2000: clinical analysis of 31 patients. J Pediatr Endocrino Metab 2002;15:823-30.

4. Azizi F, Daftarian N. Side-effects of iodized oi administration in patients with simple goiter. $J$ Endocrinol Invest 2001;24:72-7.

5. Burgess JR. Temporal trends for thyroid carcinoma in Australia: an increasing incidence of papillary thyroid carcinoma (1982-1997). Thyroid 2002;12:141-9.

6. Burgess JR, Dwyer T, McArdle K, Tucker P Shugg $D$. The changing incidence and spectrum of thyroid carcinoma in Tasmania (1978-1998) during a transition from iodine sufficiency to iodine deficiency. J Clin Endocrinol Metab 2000;85:1513-7.

7. Delange F, Lecomte P. lodine supplementation benefits outweigh risks. Drug Saf 2000;22:89-95. 8. Quadbeck B, Pruellage J, Roggenbuck U, Hirche
$\mathrm{H}$, Janssen OE, Mann K, et al. Long-term followup of thyroid nodule growth. Exp Clin Endocrino Diabetes 2002;110:348-54.

9. Welker MJ, Orlov D. Thyroid nodules. Am Fam Physician 2003;67:559-66.

10. Lawrence W Jr, Kaplan BJ. Diagnosis and management of patients with thyroid nodules. $\mathrm{J}$ Surg Oncol 2002;80:157-70.

11. Iwata $M$, Kasagi $K$, Hatabu $H$, Misaki $T$, lida $Y$, Fujita $T$, et al. Causes of appearance of scintigraphic hot areas on thyroid scintigraphy analysed with clinical features and comparative ultrasonographic findings. Ann Nucl Med 2002;16:279-87.

12. Vidal-Trecan GM, Stahl JE, Durand-Zaleski I. Managing toxic thyroid adenoma: a cost effectiveness analysis. Eur $\mathrm{J}$ Endocrinol 2002;146:283-94.

13. Brkljacic B, Sucic M, Bozikov V, Hauser M Hebrang A. Treatment autonomous and toxic thyroid adenomas by percutaneous ultrasoundguided ethanol injection. Acta Radiol 2001;42:477-81.

14. Abdullah M. Thyroid cancer: The Kuala Lumpur experience. ANZ J Surg 2002;72:660-4

15. Lawal O, Agbakwuru A, Olayinka OS, Adelusola $\mathrm{K}$. Thyroid malignancy in endemic nodular goiters: prevalence, pattern and treatment. Eur J Surg Oncol 2001;27:157-61.

16. Meller J, Becker W. The continuing importance of thyroid scintigraphy in the era of highresolution ultrasound. Eur J Nucl Med M $\mathrm{I}$ Imag 2002;29:S425-38.

17. Kountakis SE, Skoulas IG, Maillard AA. The radiologic work-up in thyroid surgery: fine-needle biopsy versus scintigraphy and ultrasound. Ear Nose Throat J 2002;81:151-4.

18. Wagana LN, Mwangi I, Bird P, Hill AG. Management of solitary thyroid nodules in rura Africa. East Afr Med J 2002;79:584-7.

19. Bahar G, Braslavsky D, Shpitzer T, Feinmesser $\mathrm{R}$, Avidan S, Popovtzer A, et al. The cytological and clinical value of the thyroid "follicular lesion".
Am J Otolaryngol 2003;24:217-20.

20. Leenhardt L, Menegaux F, Franc B, Delbot T, Mansour G, Hoang C, et al. Selection of patients with solitary thyroid nodules for operation. Eur $\mathrm{J}$ Surg 2002;168:236-41.

21. Papini E, Guglielmi R, Bianchini A, Crescenzi A Taccogna S, Nardi F, et al. Risk of malignancy in non-palpable thyroid nodules: predictive value of ultrasound and color-Doppler features. J Clin Endocrinol Metab 2002;87:1941-6.

22. Stojadinovic A, Fields SI, Shriver CD, Lenington S, Ginor R, Peoples GE, et al. Electrical impedence scanning of thyroid nodules before thyroid surgery: a prospective study. Ann Surg Oncol 2005;12:152-60.

23. Jun $P$, Chow LC, Jeffrey RB. The sonographic features of papillary thyroid carcinomas: pictorial essay. Ultrasonud Q 2005;21:39-45.

24. Ishigaki S, Shimamoto K, Satake H, Sawaki A, Itoh S, Ikeda M, et al. Multi-slice CT of thyroid nodules: comparison withultrasonography. Radiat Med 2004;22:346-53.

25. Kang HW, No JH, Chung JH, Min YK, Lee MS, Lee MK, et al. Prevalence, clinical, and ultrasonographic characteristics of thyroid incidentalomas. Thyroid 2004;14:29-33.

26. Mansi L, Moncayo R, Cuccurullo V, Dottorini ME, Rambaldi PF. Nuclear medicine in diagnosis, staging and follow-up of thyroid cancer. Q J Nucl Med Mol Imaging 2004;48:82-95.

27. Bulow PI, Knudsen N, Jorgensen T, Perrild H, Ovesen L, Laurberg P. Large differences and incidences of overt hyper- and hypothyroidism associated with a small difference in iodine intake: a prospective comparative register-based population survey. J Clin Endocrinol Metab 2002;87:4462-9.

28. Haber RS. Role of ultrasonography in the diagnosis and management of thyroid cancer. Endocr Pract 2000;6:396-400.

29. Khoo ML, Asa SL, Witterick IJ, Freeman JL. Thyroid calcification and its association with thyroid carcinoma. Head neck 2002;24:651-5. 
30. Alexander EK, Marqusee E, Orcutt J, Benson CB, Frates MC, Doubilet PM, et al. Thyroid nodule shape and prediction of malignancy. Thyroid 2004;14:953-8.

31. Neuhold N, Kaiser H, Kaserer K. Latent carcinoma of the thyroid in Austria: a systemic autopsy study. Endocr Pathol 2001;12:23-31.

32. Mishra A, Agarwal A, Agarwal G, Mishra SK. Total thyroidectomy for benign thyroid disorders in an endemic region. World J Surg 2001;25:307-10.

33. Mikosch P, Gallowitsch HJ, Kresnik E, Jester J, Wurtz FG, Kerschbaumer K, et al. Value of ultrasound-guided fine-needle aspiration biopsy of thyroid nodules in an endemic goiter area. Eur J Nucl Med 2000;27:62-9.
34. Bakiri F, Djemli FK, Mokrane LA, Djidel FK. The relative roles of endemic goiter and socioeconomic development status in the prognosis of thyroid carcinoma. Cancer 1998;15:1146-53.

35. Mishra A, Mishra SK, Agarwal A, Das BK, Agarwal G, Gambhir S. Metastatic differentiated thyroid carcinoma: clinicopathological profile and outcome in an iodine deficient area. World J Surg 2002;26:153-7.

36. Slowinska-Klencka D, Klencki M, Sporny S, Lewinski A. Fine-needle aspiration biopsy of the thyroid in an area of endemic goiter: influence of restored sufficient iodine supplementation on the clinical significance of cytological results. Eur $\mathrm{J}$ Endocrinol 2002;146:19-26.

Indian Journal of Medical Sciences is pleased to announce the launch of its website. The URL of the website is http://www.indianjmedsci.org.

The features of the site are:

- Free full text availability of articles in HTML as well as PDF

- Link to abstracts and full text from the cited references

- Link to PubMed abstracts of published articles by authors

- Link to related articles in PubMed

- Link from text of articles to various databases and search engines

- Facility to submit comments on articles

- Email notifications on new issue release

- Statistics of articles download and visits

- Structure based on OpenURL, DC Metadata and other international standards 